\title{
A meta-review of evidence on heart failure disease management programs: the challenges of describing and synthesizing evidence on complex interventions
}

\author{
Lori A Savard', David R Thompson ${ }^{2}$ and Alexander M Clark ${ }^{1 *}$
}

\begin{abstract}
Background: Despite favourable results from past meta-analyses, some recent large trials have not found Heart Failure (HF) disease management programs to be beneficial. To explore reasons for this, we evaluated evidence from existing meta-analyses.

Methods: Systematic review incorporating meta-review was used. We selected meta-analyses of randomized controlled trials published after 1995 in English that examined the effects of HF disease management programs on key outcomes. Databases searched: MEDLINE, EMBASE, Cochrane Database of Systematic Reviews (CDSR), DARE, NHS EED, NHS HTA, Ageline, AMED, Scopus, Web of Science and CINAHL; cited references, experts and existing reviews were also searched.

Results: 15 meta-analyses were identified containing a mean of 18.5 randomized trials of HF interventions $+/-10.1$ (range: 6 to 36). Overall quality of the meta-analyses was very mixed (Mean AMSTAR Score $=6.4+/-1.9$; range 2-9). Reporting inadequacies were widespread around populations, intervention components, settings and characteristics, comparison, and comparator groups. Heterogeneity (statistical, clinical, and methodological) was not taken into account sufficiently when drawing conclusions from pooled analyses.

Conclusions: Meta-analyses of heart failure disease management programs have promising findings but often fail to report key characteristics of populations, interventions, and comparisons. Existing reviews are of mixed quality and do not adequately take account of program complexity and heterogeneity.
\end{abstract}

\section{Background}

Heart failure (HF) disease management programs are common in North America, Europe, and Australia [1,2]. These services provide care to optimize pharmacological regimen and support medication management and effective self-care. Programs have been widely introduced following recommendations from international clinical guidelines $[1,3,4]$ but a number of recent and comparatively large trials have found no or small benefits from programs [5-10]. These inconsistencies have been explained by design issues rather than biases, reporting

\footnotetext{
* Correspondence: alex.clark@ualberta.ca

'University of Alberta, $3^{\text {rd }}$ Floor, Clinical Sciences Building, Edmonton, $A B$, T6G 2G3, Canada

Full list of author information is available at the end of the article
}

inadequacies or differences in actual effects [11,12]. However, recent results from the United States of the Medicare Health Support Pilot Program (MHSPP) [13] provide corroboration that program effects are poorly understood. This independent randomized trial of nine disease management programs with 30,000 patients with heart failure and diabetes concluded that programs did not decrease mortality, frequency of hospitalization, costs, or improve self-care, self-care efficacy, or mental and physical health [13].

These results raise questions about what clinicians should do in the light of contradictory evidence from trials and meta-analyses. When results from trials differ, it should not be concluded that an intervention is ineffective because most trials are underpowered to identify

\section{C) Biomed Central}


true effects [14]. Meta-analyses can overcome this lack of power but are as prone to reporting and design flaws as any other type of research design [15]. Though findings from meta-analyses frequently influence guidelines, like any other research design, as the recent PRISMA guidelines acknowledge, systematic reviews can vary widely in quality $[16,17]$.

Thus, the methods and overall quality of meta-analysis are of great importance. Despite this, there has been no systematic appraisal of the quality of meta-analyses of heart failure management programs to date. This is particularly important given the increasing awareness of the complexity and diversity of these programs [18]. To evaluate the strength of evidence from current metaanalyses of these programs, we appraised the nature and quality of evidence from existing published meta-analyses of HF disease management programs.

\section{Methods}

Meta-review was used to identify and appraise evidence from published meta-analyses of heart failure disease management programs or approaches. Meta-review appraises and synthesises findings from systematic reviews, in this instance, from meta-analyses [19]. The approach has evolved in response to the growing number of systematic reviews and the need to appraise quality of a review before application to practice and policy, for example via PRISMA [17].

Meta-review follows similar principles to systematic review [19]: it involves a comprehensive and detailed search of the literature for relevant studies with quality assessment to assess for bias, transparency, and comprehensiveness [19]. As with traditional systematic review, in meta-review, validation of quality by a second, independent reviewer is important to reduce potential for bias [19].

A comprehensive search was done to identify metaanalyses of randomized controlled trials published in English that examined the effects of HF disease management programs on key outcomes. To be included, reviews had to have a detailed and comprehensive search strategy (as identified by: naming of databases and years of searching and example or actual terms), contain data on study quality and make reference to synthesis of findings either by pooling data or rejecting the pooling of data. Due to changes in clinical practice, and to ensure some degree of congruence with contemporary clinical practice, we searched only for meta-analyses published after 1995, confined our search to reviews that contained comparisons of programs with usual care, and included samples of adults over the age of 18 years with confirmed diagnosis of HF. Meta-analyses of interventions that included patients with other forms of cardiac disease (such as cardiac rehabilitation or secondary prevention) that may have addressed heart failure disease management were not included due to the lack of data specific to heart failure populations in these reviews $[20,21]$. Finally, the meta-analyses had to contain extractable data for HF patients on mortality (all-cause or HF related), hospital (re)admission (allcause and HF related), or health-related quality of life.

For the purposes of the review, interventions were defined as HF management programs if they consisted of more than one recognized disease management component (medication optimization, lifestyle modification, or education) with the purpose of improving outcomes related to HF in patients with a confirmed diagnosis or were self-identified by the authors as constituting a program or analogous health service intervention beyond usual care for the treatment of HF.

A variety of electronic databases using a range of search terms (Table 1) were searched, including: MEDLINE, EMBASE, Cochrane Database of Systematic Reviews (CDSR), DARE, NHS EED, NHS HTA, Ageline, AMED, Scopus, Web of Science and CINAHL from $1^{\text {st }}$ January 1995 to July 31, 2008. In addition, reference lists and bibliographies of identified reviews were hand searched.

The primary screening was conducted independently by LS and AMC with abstracts/titles being screened fully. Full papers for potential inclusion were then screened by LS and AMC for detailed evaluation with disagreements regarding eligibility being handled with joint discussion between LS, AMC, and DRT.

Data were extracted onto a standardized data extraction template relating to: population, intervention, comparison, and outcome (PICO). This approach has been developed for optimizing evidence-based practice. Quality of each meta-analysis was assessed independently by LS and AMC using a standardized and valid measure of quality of systematic review (AMSTAR) [22].

\section{Results}

4529 potential articles were initially identified (Figure 1) but primary screening excluded 4285 papers. After reviewing the remaining papers $(\mathrm{n}=244), 15$ meta-analyses met the inclusion criteria (Table 2).

\section{Table 1 Search terms used}

\begin{tabular}{ll}
\hline Disease management-related & $\begin{array}{l}\text { Heart failure- } \\
\text { related }\end{array}$ \\
\hline $\begin{array}{l}\text { Disease management program (exp), } \\
\text { manag(exp), educat(exp), }\end{array}$ & $\begin{array}{l}\text { Heart failure } \\
\text { (exp) }\end{array}$ \\
$\begin{array}{l}\text { Chronic disease (exp), program(exp), coach, usual } \\
\text { care, counsel(exp), directive, organization, managed }\end{array}$ & \\
care programs, patient education, disease & \\
management (exp), care management (exp), & \\
randomized trial, program evaluation, evaluat(exp), & \\
meta-anal(exp), metaanal(exp), review(exp) & \\
\hline
\end{tabular}

Exp: Exploded search 


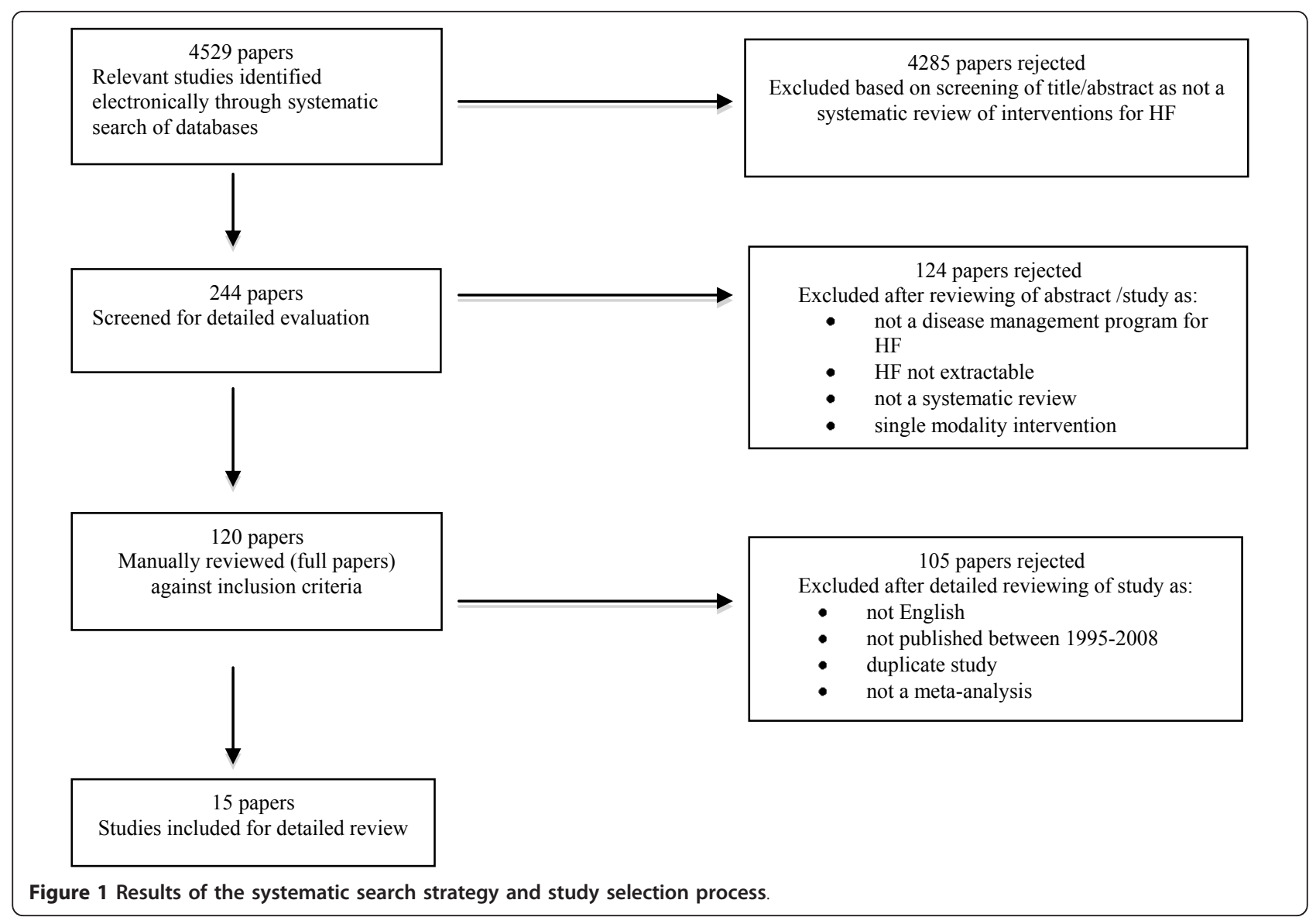

Table 2 Meta-analyses included in review

\begin{tabular}{|c|c|c|c|c|c|c|c|}
\hline $\begin{array}{l}\text { Review (Reference } \\
\text { number) }\end{array}$ & Number of trials & $\begin{array}{l}\mathrm{N} \text { of total } \\
\text { sample }\end{array}$ & $\begin{array}{l}\text { Sex } \\
\text { (\% males) }\end{array}$ & Mean Age & $\begin{array}{l}\text { SD } \\
\text { Age }\end{array}$ & $\begin{array}{l}\text { Age Range } \\
\text { (Years) }\end{array}$ & $\begin{array}{l}\text { AMSTAR } \\
\text { Score }\end{array}$ \\
\hline Koshman et al. [35] & 12 & 2060 & NR & NR & NR & $58-80$ & 7 \\
\hline Clark et al. [25] & 14 & 4264 & NR & NR & NR & $57-75$ & 8 \\
\hline Gohler et al. [32] & 36 & 8341 & $37-99 \%$ & NR & NR & $56-79$ & 5 \\
\hline Jovicic et al. [24] & 6 & 857 & $53-76 \%$ & NR & NR & $56-76$ & 7 \\
\hline Holland et al. [34] & 30 & NR & $27-99 \%$ & NR & NR & $56-80$ & 4 \\
\hline Kim \& Soeken [23] & 4 & NR & NR & NR & NR & $\begin{array}{l}\text { NR to } 64.0 \text { to } \\
81.6\end{array}$ & 6 \\
\hline Phillips et al. [31] & 6 & 949 & $58 \%$ & 73 & NR & $62-79$ & 8 \\
\hline Roccaforte et al. [28] & 33 & 3817 & $42 \%$ & 73 & NR & NR & 8 \\
\hline Taylor et al. [27] & 16 & 1627 & $23-86 \%$ & NR & NR & $70-80$ & 9 \\
\hline Whellan et al. [36] & 19 & 5752 & $\mathrm{NR}$ & NR & $\mathrm{NR}$ & $56-80$ & 2 \\
\hline Gonseth et al. [37] & $\begin{array}{l}\text { 54: } 27 \text { randomized and } 27 \text { non- } \\
\text { randomized }\end{array}$ & 3160 & NR & $\begin{array}{l}\text { Over } 70 \text { in most } \\
\text { trials }\end{array}$ & NR & $\begin{array}{l}\text { Not } \\
\text { summarized }\end{array}$ & 9 \\
\hline $\begin{array}{l}\text { Gwadry-Sridhar et al. } \\
\text { [33] }\end{array}$ & 8 & 1239 & $37-58 \%$ & NR & NR & $71-80.3$ & 6 \\
\hline McAlister et al. [30] & 29 & 5039 & NR & NR & NR & $56-80$ & 5 \\
\hline Phillips et al. [29] & 18 & 3304 & $62 \%$ & NR & NR & NR & 7 \\
\hline McAlister et al. [26] & 11 & 2067 & NR & NR & NR & $63-80$ & 5 \\
\hline
\end{tabular}


The 15 meta-analyses (Table 2 ) contained a mean of 18.5 randomized trials $+/-10.1$ (range: 6 to 36) and a mean of 3267.4 patients $+/-2184.0$. Two reviews did not report sample size $[9,23]$. Overall quality of the meta-analyses based on AMSTAR criteria [22] was moderate but varied widely (Mean Score $=6.4+/$ - 1.9; range 2-9). Main weaknesses in the reviews were lack of incorporation of study quality in conclusions and low detail regarding excluded studies (Additional file 1).

\section{Search Strategies}

Most reviews searched for published and unpublished trials [9,24-31]; four identified that grey literature was searched $[9,26,27,30]$. Though only one review limited its search to English-only papers, [32] the overall quality of search strategies was moderate: three reviews described a full Boolean strategy $[24,27,33]$ and eight provided a QUOROM-like flow chart [25,28-31,33-35]. Most reviews included an assessment of publication bias via a funnel plot [23-25,28,29,31,32,34].

\section{Populations}

Mean age of the review population was calculated in two reviews [28,31] (both mean age: 73 years) with the oldest reported mean age being 81.6 [23]. Seven reviews $[23,26,27,30,33,34,36]$ reported an upper age limit of 80 years. The lowest mean age reported was 56 by five reviews by way of inclusion of the same trial $[24,30,32,34,36]$. Two additional reviews reported lower mean age limits of 57 and 58 [25,35] but none presented data on standard deviation of ages.

Six reviews $[23,25,26,30,35,36]$ provided no data on the sex of the participants in the trials. Co-morbidities and characteristics of study populations were frequently not reported with particular weaknesses in reporting of medication treatments (Table 3). Of the four studies that did report co-morbidities, [26,31,36,37] hypertension, diabetes, chronic obstructive lung disease, and coronary artery disease were most common.

\section{Interventions}

\section{Definitions of trials}

Reviews most frequently used operationalised definitions (Table 4) to guide inclusion of interventions, though only three used definitions involving approach, personnel, setting, and content [23,26,27]. The foci of reviews differed markedly, for example, reviews specified interventions provided only in particular settings, [23,25-27] or without reference at all to content [25,34,37].

\section{Interventions included}

Interventions included in reviews mostly spanned three to five patient settings or modes of provision; only two were focused on interventions using single or comparable settings or mode of provision [23,25]. Interventions included in reviews were wide ranging (Table 4) in terms of number and type of settings and locations. For example, nine reviews included programs with both hospital and homebased components [27-29,31,33-37] and two reviews included studies that employed interventions in all settings $[29,34]$. Nurses were the most frequent providers of care through 'multi-disciplinary team' interventions. Additional physician involvement via cardiologist or general practitioner was identified in nine reviews [26,28-32,35-37] though three reviews involved both general practitioners and cardiologists [26,30,36]. All reviews but one [24] identified other personnel involved, for example: pharmacist or pharmacist collaboration [28-30,32,35,37].

\section{Program Content}

The reviews specified a mean of 1.13 essential components of content (range 0 to 3 ). Interventions were described in terms of content using general descriptors, such as education, self-care, discharge plan, and medication support. Reviews most commonly stated that interventions had to have three or four component items though reviews could extend to five or more content components [26,30,37]. Educational and monitoring interventions were the most commonly identified elements. Other components included support at hospital discharge, medication review, and social support. Hence,

Table 3 Select population characteristics

\begin{tabular}{lll}
\hline Reporting of population characteristics & & \\
\hline No information on co-morbidities & $7 / 15$ & {$[24,25,29,30,32,33,35]$} \\
\hline Incomplete or no data on NYHA Classification & $10 / 15$ & {$[9,23,24,26,27,29,30,33,35-37]$} \\
\hline No data on NYHA Classification & $4 / 15$ & {$[23,26,27,30]$} \\
\hline Range of NYHA Classification only & $6 / 15$ & {$[24,25,28,31,32,37]$} \\
\hline Information on LVEF & $6 / 15$ & {$[25,29,31,34,36,37]$} \\
\hline Summaries of ACE-I and BB medication treatments & $3 / 15$ & {$[32,36,37]$} \\
\hline
\end{tabular}

${ }^{\mathrm{a} N Y H A}$, New York Heart Association

${ }^{b}$ LVEF, Left Ventricular Ejection Fraction

${ }^{c} A C E-I$, Ace-Inhibitor

${ }^{\mathrm{d} B \mathrm{~B} \text {, Beta Blocker }}$ 
Table 4 Definitions of trials and characteristics of interventions actually included

\begin{tabular}{|c|c|c|}
\hline \multicolumn{3}{|l|}{ Definitions of interventions included in reviews } \\
\hline No definition & $1 / 15$ & [33] \\
\hline Operationalized definition & $11 / 15$ & {$[23-27,30-32,34,36,37]$} \\
\hline Definitions incorporate approach, personnel, setting and content & $3 / 15$ & {$[23,26,27]$} \\
\hline Concept of a disease management program & $5 / 15$ & {$[26,28,30,31,36]$} \\
\hline Concept of comprehensive treatment approach & $6 / 15$ & {$[23,24,27,29,34,37]$} \\
\hline Interventions provided in particular settings & $4 / 15$ & {$[23,25-27]$} \\
\hline \multicolumn{3}{|l|}{ Intervention Settings } \\
\hline Five settings/modes of provision & $2 / 15$ & {$[29,34]$} \\
\hline Four settings & $7 / 15$ & {$[27,30,31,33,35-37]$} \\
\hline Three settings & $4 / 15$ & {$[24,26,28,32]$} \\
\hline Single or comparable setting & $2 / 15$ & {$[23,25]$} \\
\hline \multicolumn{3}{|l|}{ Type of setting } \\
\hline All settings & $2 / 15$ & {$[29,34]$} \\
\hline Hospital (Pre-discharge) & $10 / 15$ & {$[23,27-29,31,33-37]$} \\
\hline Hospital and home-based components & $9 / 15$ & {$[27-29,31,33-37]$} \\
\hline Home and community & 9/15 & {$[27-29,31,33-37]$} \\
\hline At home & $13 / 15$ & {$[24,26-37]$} \\
\hline Out-patient & $13 / 15$ & {$[24,26-37]$} \\
\hline Telephone & $11 / 15$ & {$[24,25,27,29-35,37]$} \\
\hline Remote provision & $5 / 15$ & {$[25,29,30,34,36]$} \\
\hline \multicolumn{3}{|l|}{ Professionals } \\
\hline Nurse-led & $11 / 15$ & {$[23,24,26,28-32,34,36,37]$} \\
\hline 'Multi-disciplinary teams' & $10 / 15$ & {$[23,25,26,28,30,32-35,37]$} \\
\hline Physician involvement via cardiologist or GP & $9 / 15$ & {$[26,28-32,35-37]$} \\
\hline Both cardiologist and GP & $3 / 15$ & {$[26,30,36]$} \\
\hline Pharmacist & $6 / 15$ & {$[28-30,32,35,37]$} \\
\hline
\end{tabular}

a degree of overlap existed across settings. For example, a systematic review may focus on a nurse-led hospitalbased intervention yet offers home visits, telephone support, and follow-up with a general practitioner [23].

Obtaining data on usual care was noted to be problematic [23,27-29,32,35] and the care provided to comparison groups was poorly defined (Table 5). For example, in seven of twelve trials in one review, descriptions of care were omitted entirely [35].

\section{Outcomes}

The follow-up period was 3 to 12 months in six reviews $[24,27,29,31,33,36]$. Three studies reported beginning follow-up periods at three months but the upper limit extended to 16, 18, and 22 months [25,32,28]. Other reviews did not report length of follow-up [34] or did not report follow-up periods [23].

\section{Within review pooling of outcomes}

The meta-analyses pooled data on: all-cause mortality as primary and secondary outcomes. (Table 6) Other outcomes pooled included all-cause (re)admission, HF mortality, HF (re)admission, quality of life, and cost. Data were pooled using random [25,28,30,32-35] and fixed effect models of analysis [24,27] or both methods $[26,29,31,37]$ if significant statistical heterogeneity was identified.

Table 5 Components of interventions included and trial quality

\begin{tabular}{lll}
\hline Number of components & & \\
\hline $3-4$ & $8 / 15$ & {$[23,24,27-29,31,32,35]$} \\
\hline $\mathbf{4}$ & $3 / 15$ & {$[26,30,37]$} \\
\hline Educational components & $13 / 15$ & {$[23,24,26-35,37]$} \\
\hline Monitoring via home visits or phone & $13 / 15$ & {$[23,24,26-32,34-37]$} \\
\hline Support at hospital discharge & $10 / 15$ & {$[23,24,26,28-32,36,37]$} \\
\hline Medication review & $9 / 15$ & {$[24,26-28,30-32,35,37]$} \\
\hline Social support & $5 / 15$ & {$[26,27,29,30,37]$} \\
\hline Comparison Groups & & \\
\hline No information & $11 / 15$ & {$[23-26,29-31,33,34,36,37]$} \\
\hline
\end{tabular}


Table 6 Effect sizes of primary outcomes of reviews (95\% Confidence Intervals)

\begin{tabular}{|c|c|c|c|}
\hline Review (reference number) & All cause mortality & All cause re-hospitalization & HF-related hospitalization \\
\hline Koshman et al. [35] & OR $0.84(0.61-1.15)$ & OR $0.71(0.54-0.94)$ & OR $0.69(0.51-0.94)$ \\
\hline Clark et al. [25] & RR 0.80 (0.69-0.92) & RR 0.95 (0.89-1.02) & RR 0.79 (0.69-0.89) \\
\hline Gohler et al. [32] & RD $0.03(0.01-0.05)$ & RD $0.08(0.05-0.11)$ & NA \\
\hline Jovicic et al. [24] & OR $0.93(0.57-1.51)$ & OR $0.59(0.44-0.80)$ & OR $0.44(0.27-0.71)$ \\
\hline Holland et al. [34] & RR 0.79 (0.69-0.92) & RR $0.84(0.79-0.95)$ & RR $0.70(0.61-0.81)$ \\
\hline Kim \& Soeken [23] & NA & OR 0.87 (0.69-1.04) & NA \\
\hline Phillips et al. [31] & RR 0.80 (0.57-1.13) & RR 0.91 (0.72-1.16) & NA \\
\hline Roccaforte et al. [28] & OR $0.80(0.69-0.93)$ & OR $0.76(0.69-0.94)$ & OR $0.58(0.50-0.67)$ \\
\hline Taylor et al. [27] & OR $0.86(0.67-1.10)$ & NA & OR $0.52(0.39-0.70)$ \\
\hline Whellan et al. [36] & NA & NA & NA \\
\hline Gonseth et al. [37] & RR $0.75(0.59-0.96)$ & RR $0.88(0.79-0.97)$ & RR $0.70(0.62-0.79)$ \\
\hline Gwadry-Sridhar et al. [33] & RR 0.98 (0.72-1.34) & RR $0.79(0.68-0.91)$ & NA \\
\hline McAlister et al. [30] & RR 0.83 (0.70-0.99) & RR $0.84(0.75-0.93)$ & RR $0.73(0.66-0.82)$ \\
\hline Phillips et al. [29] & RR 0.87(0.73-1.03) & RR 0.75 (0.64-0.88) & RR 0.65 (0.54-0.79) \\
\hline McAlister et al. [26] & RR 0.94 (0.75-1.19) & RR $0.87(0.79-0.96)$ & NA \\
\hline
\end{tabular}

RR: Risk Ratio; RD: Risk Difference; OR: Odds Ratio

Out of 13 reviews, 6 identified statistically significant improvements in all cause mortality $[25,28,30,32,34,37]$ though all 13 reviews identified trends favouring programs over control. Effect sizes varied from 3\% to $25 \%$ but were mostly clustered around $15 \%$ to $20 \%$. Larger benefits were more evident in terms of hospitalisations. All 9 reviews that measured changes in HF-related hospitalizations [24,25,27-30,34,35,37] identified significant reductions in admissions with reductions in risk ranging from $30 \%$ to $56 \%$. Out of 13 reviews, 10 reviews $[24,26,28-30,32-35,37]$ identified reductions in all-cause readmission with reductions in risk ranging from $8 \%$ to $41 \%$ with most clustered around $15 \%$ to $25 \%$ reductions in admission. Seven reviews extracted data on quality of life or health-related quality of life [27-31,33,35]. (Table 7) The majority did not pool outcomes due to high levels of heterogeneity $[27,28,33,35]$ or lack of data [30]. However, two reviews identified insignificant trends favouring quality of life improvements after pooling $[29,31]$.

Due to the limited reporting of interventions and control groups and the diversity of trials included in the reviews, it is not appropriate to pool outcomes from the meta-analyses here. This is important because findings from interventions that are excessively heterogeneous should not be pooled. Particularly, this was the case with these meta-analyses that varied and/or contained unclear data pertaining to a wide range of factors and strata of programs, for example, relating to clinical populations, providers, location, mode of delivery, numbers of components, and length. These multiple ambiguities made pooling, sensitivity analysis, and metaregression inappropriate [38-40].
Handling of uncertainty in the reporting of review results Trial quality was inconsistently taken into account when formulating conclusions and was not addressed in most reviews. Statistical heterogeneity was discussed in most reviews though clinical and methodological heterogeneity was consistently neglected (Table 8 ). Sensitivity analyses were carried out around a diverse range of elements, including study quality, [23,28-30,34,35,37] size, [37] and publication status [34]. Intervention-type, $[26,28]$ follow up, [26,30] diagnoses, [23] and elements of interventions related to: components, $[23,26]$ complexity, [31] and provider-type [28,37]. Three reviews selected factors a priori for sensitivity analysis $[26,30,37]$. Sub-analyses were undertaken around 'general' program features, [32] setting, [26,30,34] home-visit or telephone contact, [26] and discharge planning $[29,31]$.

\section{Discussion}

This meta-review is the first of meta-analyses of HF disease management programs and conveys the challenges of performing meta-analyses of complex health services interventions. Overall, quality of the reviews was moderate though very mixed across reviews - this quality is important to consider when deciding whether review findings should guide practice and guidelines [22,41,42].

Based on the consistency and size of effect sizes identified by the meta-analyses, it would immediately appear reasonable to conclude either that, in generality, programs work or that programs of various types work [43]. However, this meta-review supports concerns that populations, programs, and analyses of these programs are inconsistently and poorly described $[44,45]$. For 
Table 7 Direction of effects Quality of Life

\begin{tabular}{|c|c|c|c|}
\hline Review & Measures & Pooling (Y/N) & Result of pooling \\
\hline $\begin{array}{l}\text { Phillips et al. (2005) } \\
\text { [31] }\end{array}$ & $\begin{array}{l}\text { NHP } \\
\text { MLHF } \\
\text { HFSBS }\end{array}$ & $\begin{array}{c}\text { Y } \\
\text { (5/6 studies reported QOL) }\end{array}$ & $\begin{array}{c}+ \\
\text { Intervention: } 30.6 \pm 20.7 \% \text { VS. control: } 19.3 \pm 12.6 \% \\
p=0.13\end{array}$ \\
\hline $\begin{array}{l}\text { Gwadry-Sridhar et al. } \\
\text { (2004) [33] }\end{array}$ & SF-36 & $\begin{array}{c}\mathrm{N} \\
\text { (4/8 studies reported HRQOL; precluded pooling) }\end{array}$ & RNPH \\
\hline $\begin{array}{l}\text { Koshman et al. } \\
\text { (2008) [35] }\end{array}$ & $\begin{array}{c}\text { MLHF } \\
\text { COOP/WONCA } \\
\text { SF-36 } \\
\text { EQ-5D } \\
\text { CHFQ }\end{array}$ & $\begin{array}{c}\mathrm{N} \\
\text { (7/12 studies reported HRQOL; precluded pooling) }\end{array}$ & $\mathrm{RNPH}$ \\
\hline $\begin{array}{l}\text { Roccaforte et al. } \\
\quad(2005)[28]\end{array}$ & $\begin{array}{l}\text { MLHF } \\
\text { SF-36 }\end{array}$ & $\begin{array}{l}\mathrm{N} \\
\text { (16/33 studies reported QOL; varying presentation } \\
\text { of results precluded pooling) }\end{array}$ & $\mathrm{RNPH}$ \\
\hline $\begin{array}{c}\text { Taylor et al. (2005) } \\
\text { [27] }\end{array}$ & $\begin{array}{c}\text { MLHF } \\
\text { QLHFQ } \\
\text { CHFQ } \\
\text { Time trade off } \\
\text { method (?) }\end{array}$ & (8/16 studies reported HRQOL; varying results) & $\mathrm{RNPH}$ \\
\hline $\begin{array}{l}\text { Phillips et al. (2004) } \\
\text { [29] }\end{array}$ & $\begin{array}{l}\text { MLHF } \\
\text { NHP } \\
\text { HFSBS } \\
\text { SF-36 }\end{array}$ & $\begin{array}{c}\mathrm{Y} \\
\text { (5/18 studies reported HRQOL) }\end{array}$ & $\begin{array}{c}\text { Intervention: } 25.7 \%[95 \% \mathrm{Cl}, 11.0 \%-40.4 \%] \text { VS. control: } \\
13.5 \%[95 \% \mathrm{Cl}, 5.1 \%-22.0 \%]\end{array}$ \\
\hline $\begin{array}{l}\text { McAlister et al. } \\
\text { (2001) [26] }\end{array}$ & NR & N (5/11 studies reported HRQOL) & Insufficient data \\
\hline
\end{tabular}

$\mathrm{HRQOL}=$ Health-related quality of life; QOL = Quality of life

MLHF = Minnesota Living with Heart Failure Questionnaire; COOP/WONCA = Dartmouth Primary Care Cooperative Research Network/World Organization of National Colleges, Academics and Academic Associations of General Practitioners/Family Physicians; SF-36 = 36-Item Short-Form Health Survey; EQ-5D = EuroQol5 Dimensions form

NHP = Nottingham Health Profile; HFSBS = Heart Failure Self Care Behaviour Scale; QLHFQ = Quality of Life in Heart Failure Questionnaire; CHFQ = Chronic Heart Failure Questionnaire

RNPH: Results not pooled due to heterogeneity

$+=$ Non-significant trend favoring intervention

$++=$ Significant trend favoring intervention

example, studies were poorly described in terms of populations and treatments with only one-fifth of reviews defining programs comprehensively in terms of approach, personnel, setting, and content. Even with the use of operationalised definitions to guide study selection in reviews, findings from interventions with very diverse characteristics and populations were pooled and, though mentioned in reviews, the implications of trial

Table 8 Trial quality and heterogeneity

\begin{tabular}{ll}
\hline Conclusions \\
\hline Quality & \\
\hline Trial quality taken into account & {$[35,37]$} \\
\hline Trial quality mentioned & {$[23,24,27,33]$} \\
\hline Heterogeneity & \\
\hline Discussed & {$[27,28,30,32,34,35,37]$} \\
\hline Statistical Assessment & {$[23-35,37]$} \\
\hline Cochran's Q test and I ${ }^{2}$ statistic & {$[23-35,37]$} \\
\hline Clinical acknowledged & {$[24,25,32]$} \\
\hline Methodological acknowledged & {$[26,33,35]$} \\
\hline
\end{tabular}

quality or statistical, clinical or methodological heterogeneity were seldom actually taken into account in analyses. No progress over time was evident in quality of reporting. Hence, reviews continue to focus on the results of study pooling over issues related to program complexity and heterogeneity.

Why might program complexity and heterogeneity be comparatively neglected in comparison to the findings of reviews? Firstly, this emphasis is understandable due to limitations in methodology. Complex interventions are often poorly described in published manuscripts [46] and it is well known that HF disease management programs are complex and diverse $[43,45,47]$. Current statistical and methodological techniques to describe and analyse such interventions in systematic review remain rudimentary [48]. Current meta-analyses also predate the existence of a taxonomy to classify HF disease management programs [18] and more extensive CONSORT reporting requirements for non-pharmacological trials [49].

Secondly, scientific findings that are more positive are more likely to be published in higher impact journals 
and cited more often in guidelines [50,51]. This reduces incentives to qualify results to take account of 'messy' issues related to program diversity and heterogeneity and fosters a disproportionate emphasis on positive findings without qualification [52] or recognition of how elements of context may moderate intervention effects [53]. This tendency may be combined with a wider perceived political need to champion multi-disciplinary health services interventions to attain greater recognition and usage of such interventions in healthcare systems seen to favour pharmacological interventions and biomedicine [54].

However, paradoxically, ignoring complexity and heterogeneity may actually reduce knowledge translation. This follows because uptake is likely to be reduced by unclear descriptions of what programs and comparison groups consist of, lack of clarity over likely benefits in important patient groups (for example: the effects of both age and sex on program outcomes are not known), and lack of specificity in findings regarding key program characteristics $[16,53]$.

In future reviews, programs should be described comprehensively using systematic classification methods [18]. More sophisticated taxonomies are needed to fully capture the deeper characteristics of programs [48]. These should be used in future reviews to describe programs comprehensively and the effects of clinical, methodological, and statistical heterogeneity - as per PRISMA guidelines - must be formally taken into account in methods and conclusions [15]. Future trials should report key elements of populations, interventions, comparison group, and outcomes in accordance with the modified CONSORT statement for non-pharmacological trials [49]. These factors should be incorporated and reported comprehensively in meta-analyses. Findings from meta-analyses should be evaluated prior to application to practice and policy with review quality being assessed using valid quality criteria [15].

In terms of limitations, as with any review, this metareview was constrained by the quality of reporting of the component studies. The data presented here are descriptive because it was inappropriate to synthesise outcomes to generate pooled effect sizes due to the wide diversity of programs subsumed in the reviews and the lack of comprehensive reporting in the reviews of intervention, comparator groups, and population characteristics $[55,56]$. As pivotal elements of programs, reporting of these components has to be clear and comprehensive if synthesis is to be undertaken.

\section{Conclusions}

Meta-analyses of heart failure disease management programs have promising findings but often fail to report key characteristics of populations, interventions, and comparisons. Existing reviews are of mixed quality and do not adequately take account of program complexity and heterogeneity.

\section{Additional material}

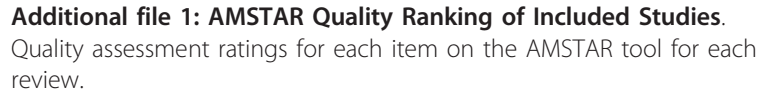

\section{Abbreviations}

HF: heart failure

\section{Acknowledgements and funding}

AMC receives career award support from Alberta Heritage Foundation for Medical Research and the Canadian Institutes for Health Research. Alberta Heritage Foundation for Medical Research: http://www.ahfmr.ab.ca/ Canadian Institutes of Health Research: http://www.cihr.ca/

The funders had no role in the study design, data collection and analysis, decision to publish, or preparation of the manuscript.

\section{Author details}

${ }^{1}$ University of Alberta, $3^{\text {rd }}$ Floor, Clinical Sciences Building, Edmonton, AB, T6G 2G3, Canada. ${ }^{2}$ Department of Health Sciences and Department of Cardiovascular Sciences, University of Leicester, Leicester, LE1 6TP, UK.

\section{Authors' contributions}

AMC and DRT conceived the study, LAS and AMC extracted data from the reviews, and co-wrote the first and final drafts, DRT addressed issues of disagreement over interpretation of data and helped refine the manuscript. All authors read and approved the final manuscript.

\section{Competing interests}

The authors declare that they have no competing interests.

Received: 29 March 2011 Accepted: 16 August 2011

Published: 16 August 2011

\section{References}

1. Heart Failure Society of America: HFSA 2006 Comprehensive Heart Failure Practice Guideline St Paul, Minnesota: HFSA; 2006.

2. National Heart Foundation of Australia and the Cardiac Society of Australia and New Zealand (Chronic Heart Failure Guidelines Expert Writing Panel): Guidelines for the prevention, detection and management of chronic heart failure in Australia. 2006.

3. Jessup M, Abraham WT, Casey DE, Feldman AM, Francis GS, Ganiats TG, Konstam MA, Mancini DM, Rahko PS, Silver MA, et al: 2009 Focused Update: ACCF/AHA Guidelines for the Diagnosis and Management of Heart Failure in Adults: A Report of the American College of Cardiology Foundation/American Heart Association Task Force on Practice Guidelines: Developed in Collaboration with the International Society for Heart and Lung Transplantation. Circulation 2009, 119:1977-2016.

4. Task Force for Diagnosis and Treatment of Acute and Chronic Heart Failure 2008 of European Society of Cardiology, Dickstein K, Cohen-Solal A,

Filippatos G, McMurray JJ, Ponikowski P, Poole-Wilson PA, Strömberg A, van Veldhuisen DJ, Atar D, et al: ESC Guidelines for the diagnosis and treatment of acute and chronic heart failure 2008: the Task Force for the Diagnosis and Treatment of Acute and Chronic Heart Failure 2008 of the European Society of Cardiology. European Heart Journal 2008, 29:2388-2442.

5. Jaarsma T, van der Wal M, Lesman-Leegte I, Luttik M, Hogenhuis J, Veeger N, Sanderman R, Hoes A, van Gilst W, Dirk JA, Lok M, et al: Effect of moderate or intensive disease management program on outcome in patients with heart failure coordinating study evaluating outcomes of advising and counseling in heart failure $(\mathrm{COACH})$. Archives of Internal Medicine 2008, 168:316-324. 
6. Nucifora G, Albanese M, De Biaggio P, Caliandro D, Gregori D, Goss P, Miani D, Fresco C, Rossi P, Bulfoni AF, Fioretti PM: Lack of improvement of clinical outcomes by a low-cost, hospital-based heart failure management programme. Journal of Cardiovascular Medicine 2006, 7:614-622.

7. Smith B, Forkner EZB, Krasuski R, Stajduhar K, Kwan M, Ellis R, Galbreath A, Freeman G: Disease management produces limited quality-of-life improvements in patients with congestive heart failure: evidence from a randomized trial in community-dwelling patients. American Journal of Managed Care 2005, 11:701-703.

8. Nguyen V, Ducharme A, White M, Racine N, O'Meara E, Zhang B, Rouleau JL, Brophy J: Lack of long-term benefits of a 6-month heart failure disease management program. Journal of Cardiac Failure 2006, 13:287-293.

9. Holland R, Brooksby I, Lenaghan E, Ashton K, Hay L, Smith R, Shepstone L, Lipp A, Daly C, Howe A, et al: Effectiveness of visits from community pharmacists for patients with heart failure: HeartMed randomised controlled trial. British Medical Journal 2007, 334:1098.

10. Ledwidge M, Ryan E, O'Loughlin C, Ryder M, Travers B, Kieran E, Walsh A, McDonald K: Heart failure care in a hospital unit: a comparison of standard 3-month and extended 6-month programs. European Journal of Heart Failure 2005, 16:385-391.

11. Jaarsma T, van Veldhuisen D: When, how and where should we "coach" patients with heart failure: The $\mathrm{COACH}$ results in perspective. European Journal of Heart Failure 2008, 10:331-333.

12. Sochalski J, Jaarsma T, Krumholz HM, Laramee A, McMurray JJV, Naylor MD, Rich MW, Riegel B, Stewart S: What works in chronic care management: The case of heart failure. Health Affairs 2009, 28:179-189.

13. Kapp M, MccCall N, Cromwell J, Urato C, Rabiner D: Evaluation of the phase I of the Medicare Health Support Pilot Program Under traditional fee-for-service medicare: 18 month interim analysis Batimore, MA: Centers for Medicare \& Medicaid Services; 2008.

14. Borenstein M, Hedges LV, Higgins JPT, Rothstein HR: Introduction to metaanalysis London: John Wiley; 2009.

15. Moher D, Liberati A, Tetzlaff J, Altman DG, the PRISMA Group: Preferred reporting items for systematic reviews and meta-analyses: the PRISMA statement. Open Medicine 2009, 3:123-130.

16. Glasgow RE, Emmons KM: How can we increase the translation of research into practice: Types of evidence needed. Annual Review of Public Health 2007, 28:413-433.

17. Guyatt $G$, Rennie D, Meade M, Cook D: User's guide to the medical literature NY, New York: American Medical Association; 2008

18. Krumholz H, Currie P, Riegel B, Phillips CO, Peterson ED, Smith R, Yancy CW Faxon DP: A taxonomy for disease management: A scientific statement from the American Heart Association Disease Management Taxononmy Writing Group. Circulation 2006, 114:1432-1445.

19. Whitlock E, Lin J, Chou R, Shekelle P, Robinson K: Using exisiting systematic reviews in complex systematic reviews. Annals of Internal Medicine 2008, 148:776-782

20. Taylor RS, Brown A, Ebrahim S, Jolliffe J, Noorani H, Rees K, Skidmore B, Stone J, Thompson DR, Oldridge N: Exercise-based rehabilitation for patients with coronary heart disease: systematic review and metaanalysis of randomized controlled trials. American Journal of Medicine 2004, 116:682-692

21. Clark AM, Hartling L, Vandermeer B, MCAlister FA: Secondary prevention program for patients with coronary artery disease: A meta-analysis of randomized control trials. Annals of Internal Medicine 2005, 143:659-672.

22. Shea B, Grimshaw J, Wells G, Boers M, Andersson N, Hamel C, Porter AC Tugwell P, Moher D, Bouter IM: Development of AMSTAR: a measurement tool to assess the methodological quality of systematic reviews. BMC Medical Research Methodology 2007, 7(10)

23. Kim Y, Soeken KL: A meta-analysis of the effect of hospital-based case management on hospital length of stay and readmission. Nursing Research 2005, 54:255-264.

24. Jovicic A, Holroyd-Leduc JM, Straus SE: Effects of self-management intervention on health outcomes of patients with heart failure: a systematic review of randomized controlled trials. BMC Cardiovascular Disorders 2006, 6:43.

25. Clark R, Inglis S, McAlister F, Cleland J, Stewart S: Telemonitoring or structured telephone support programmes for patients with chronic heart failure: systematic review and meta-analysis. British Medical Journal 2007, 334:942

26. McAlister F, Lawson FME, Teo KK, Armstrong PW: A systematic review of randomized trials of disease management programs in heart failure. American Journal of Medicine 2001, 110:378-384.

27. Taylor S, Bestall J, Cotter S, Falshaw M, Hood S, Parsons S, Wood L, Underwood M: Clinical service organization for heart failure. The Cochrane Library 2005, 3.

28. Roccaforte R, Demers C, Baldassarre F, Teo KK, Yusuf S: Effectiveness of comprehensive disease management programmes in improving clinical outcomes in heart failure patients; a meta-analysis. European Journal of Heart Failure 2005, 7:1133-1144.

29. Phillips CO, Wright SM, Kern DE, Singa RM, Shepperd S, Rubin HR: Comprehensive discharge planning with postdischarge support for older patients with congestive heart failure: A meta-analysis. Journal of the American Medical Association 2004, 291:1358-1367.

30. McAlister F, Stewart S, Ferrua S, McMurray Jj: Multi-disciplinary strategies for the management of heart failure patients at high risk of admission: A systematic review of randomized trials. Journal of the American College of Cardiology 2004, 44:810-819.

31. Phillips CO, Singa RM, Rubin HR, Jaarsma T: Complexity of program and clinical outcomes of heart failure disease management incorporating specialist nurse-led heart failure clinics. A meta-regression analysis. European Journal of Heart Failure 2005, 7:333-341.

32. Gohler A, Januzzi J, Worrell SS, Osterziel KJ, Scott G, Dietz R, Siebert U: A systematic meta-analysis of the efficacy and heterogeneity of disease management programs in congestive heart failure. Journal of Cardiac Failure 2006, 12:554-567.

33. Gwadry-Sridhar FH, Flintoft V, Lee DS, Lee H, Guyatt GH: A systematic review and meta-analysis of studies comparing readmission rates and mortality rates in patients with heart failure. Archives of Internal Medicine 2004, 164:2315-2320.

34. Holland R, Battersby J, Harvey I, Lenaghan E, Smith J, Hay L: Systematic review of multidisciplinary interventions in heart failure. Heart 2005, 91:899-906.

35. Koshman S, Charrois T, Simpson S, McAlister F, Tsuyuki R: Pharmacist care of patients with heart failure: A systematic review of randomized trials. Archives of Internal Medicine 2008, 168:687-694.

36. Whellan DJ, Hasselblad V, Peterson E, O'Conner C, Schulman K: Metaanalysis and review of heart failure disease management randomized controlled clinical trials. American Heart Journal 2005, 149:722-729.

37. Gonseth J, Guallar-Castillion P, Banegas J, Rodriguez-Artelajo F: The effectiveness of disease management programmes in reducing hospital re-admission in older patients with heart failure: A systematic review of published papers. European Heart Journal 2004, 25:1570-1595.

38. Xu H, Platt RW, Luo ZC, Wei S, Fraser WD: Exploring heterogeneity in meta-analyses: needs, resources and challenges. Paediatric and Perinatal Epidemiology 2008, 22:18-28.

39. Ioannidis JPA, Patsopoulos NA, Evangelou E: Uncertainty in heterogeneity estimates in meta-analyses. British Medical Journal 2007, 335:914-916.

40. Hatala R, Keitz S, Wyer P, Guyatt G, the Evidence-based Medicine Teaching Tips Working Group: Tips for learners of evidence-based medicine: 4. Assessing heterogeneity of primary studies in systematic reviews and whether to combine their results. Canadian Medical Association Journal 2005, 172:661-665

41. Smith V, Devane D, Begley C, Clarke M: Methodology in conducting a systematic review of systematic reviews of healthcare interventions. BMC Medical Research Methodology 2011, 11:15.

42. Moher D, Liberati A, Tetzlaff J, Altman DG, the PRISMA Group: Preferred reporting items for systematic reviews and meta-analyses: the PRISMA statement. British Medical Journal 2009, 339:b2535.

43. Clark AM, Thompson DR: What type of heart failure program is best? Wrong question, wrong assumption. European Jounal of Heart Failure 2010, 12:1271-1273.

44. Clark AM, Savard LA, Thompson DR: What is the strength of evidence for heart failure disease management programs? Journal of the American College of Cardiology 2009, 54:397-401.

45. Clark AM, Thompson DR: The future of heart failure disease management programs. Lancet 2008, 372:784-786. 
46. Glasziou P, Meats E, Heneghan C, Shepperd S: What is missing from descriptions of treatment in trials and reviews? British Medical Journal 2008, 336:1472-1474.

47. Konstam MA, Konstam V: Heart failure disease management: A sustainable energy source for the health care engine. Journal of the American College of Cardiology 2010, 56:379-381.

48. Shepperd S, Lewin S, Straus S, Clarke M, Eccles MP, Fitzpatrick R, Wong G, Sheikh A: Can we systematically review studies that evaluate complex interventions? PLoS Medicine 2009, 6(8):e1000086.

49. Boutron I, Moher M, Altman DG, Schulz KF, Ravaud P, the CONSORT Group: Extending the CONSORT statement to randomized trials of nonpharmacologic treatment: Explanation and elaboration. Annals of Internal Medicine 2008, 148:295-309.

50. Fanelli D: Do Pressures to Publish Increase Scientists' Bias? An Empirical Support from US States Data. PLOS ONE 2010, 5:e10271.

51. Etter JF, Stapleton J: Citations to trials of nicotine replacement therapy were biased toward positive results and high-impact-factor journals. Journal of Clinical Epidemiology 2009, 62:831-837.

52. Boutron I, Dutton S, Ravaud P, Altman DG: Reporting and interpretation of randomized controlled trials with statistically nonsignificant results for primary outcomes. Journal of the American Medical Association 2010, 303:2058-2064.

53. Pawson R: Evidence-based policy: A realist perspective London: Sage; 2006.

54. Seow H, Phillips CO, Rich MW, Spertus JA, Krumholz HM, Lynn J: Isolation of health services research from practice and policy: The example of chronic heart failure management. Journal of the American Geriatrics Society 2006, 54:535-540.

55. Tu K, Gong Y, Austin P, Jaakimanian L, Tu J: Canadian Cardiovascular Outcomes Research Team. An overview of the types of physicians treating acute cardiac conditions in Canada. Canadian Journal of Cardiology 2004, 20:282-291.

56. Ezekowitz J, van Walraven C, F M, Armstrong P, Kaul P: Impact of specialist follow-up in outpatients with congestive heart failure. Canadian Medical Association Journal 2005, 172:189-194.

doi:10.1186/1745-6215-12-194

Cite this article as: Savard et al:: A meta-review of evidence on heart failure disease management programs: the challenges of describing and synthesizing evidence on complex interventions. Trials 2011 12:194.

\section{Submit your next manuscript to BioMed Central and take full advantage of:}

- Convenient online submission

- Thorough peer review

- No space constraints or color figure charges

- Immediate publication on acceptance

- Inclusion in PubMed, CAS, Scopus and Google Scholar

- Research which is freely available for redistribution

Submit your manuscript at www.biomedcentral.com/submit 